\title{
Product Champion for Successful Innovation- A Review of the Previous Literature and Challenge for the Future
}

\author{
Seiichi Fujii*
}

College of International Management, Ritsumeikan Asia Pacific University, Beppu City, Oita Prefecture, Japan

${ }^{*}$ Corresponding author: Seiichi Fujii, College of International Management, Ritsumeikan Asia Pacific University, Beppu City, Oita Prefecture, Japan, Tel: +81 977-78-1111; E-mail: fujiis@apu.ac.jp

Received Date: June 28, 2017; Accepted Date: September 19, 2017; Published Date: September 22, 2017

Copyright: (c) 2017 Fujii S. This is an open-access article distributed under the terms of the Creative Commons Attribution License, which permits unrestricted use, distribution, and reproduction in any medium, provided the original author and source are credited.

Citation: Fujii S (2017) Product Champion for Successful Innovation- A Review of the Previous Literature and Challenge for the Future. Br J Res 4(4): 22.

\section{Abstract}

Background: This paper aims to provide discussions on product champions that are indispensable for the implementation of innovation through reviews of previous studies, and to present the issues from previous studies and the direction of future studies. Studies on product champion (hereinafter abbreviated as PC) were pioneered by Schon in the 1960s. Although the results from many researchers have been accumulated afterwards, the analysis targets have not been unified, and various analysis results tend to be handled randomly.

Methods and findings: In order to introduce new points of view on the analysis of existing PC studies, in this paper we organize previous studies, identify the issues, and propose the directions that PC studies should aim for.

Conclusion: Proceeding with reviewing previous study, identification of the issues in PC field and propose of the next directions, we suggest that the progress of PC study can be accelerated and a new research overview with a more unified perspective can be established.

\section{Key words:}

Product champion; Innovation; New product development

\section{Introduction}

To increase their operational efficiency, matured companies pursue the division of labor and the expertise that accompany it. Division of labor has become an authority and a hierarchical system specified within a company [1]. Along with that, various rules, standards and procedures are established, and employees engaged in it give priority to them and make efforts to minimize cost [2]. Division of labor creates certain inertial forces in the organization [3]. However, for the implementation of novel ideas, these rules, standards, and procedures often become obstacles [4-8]. The value of a new business, which resulted from the company's deviation from an existing framework, creates the needs of new customers. In other words, organization efficiency and the implementation of innovation are often conflicting with one another, and the implementation of innovation always meets resistance within the organization [7]. This trend is obvious especially in large companies [1,7]. Schon [9] presented the concept of Product Champion (hereinafter abbreviated as PC) as an important person who promotes new ideas to overcome such obstacles and lead innovations to success. He defined a PC as an individual who has the authority and confidence, knows how to use a company's informal system and connections, and has the influence beyond a specific area necessary for product and process developments. After that, through numerous empirical studies, PC-led championing (champion an innovation idea) was incorporated as a stage in the innovation process [10], causing it to be a general factor in both theoretical and practical aspects.

However, until now PC studies (the sequential articles that researchers picked up PC as a factor of successful innovation are called as PC studies in this paper) have not yet reached the discussions on how to train or utilize PCs or actively manage championing. While comparative studies in countries with different cultural values such as the United States, Germany, France, and South Korea have been undertaken, PC studies in Japanese companies were only discussed slightly in the 1980 s and have not been performed much. Currently, even the initial study of PC identification in a company site is not done. On the contrary, in a rapidly changing business environment, Japanese companies, which are required to establish a global competitive advantage, are forced to launch new businesses centered on radically innovative products. When Japanese companies with a long manufacturing history intend to innovate, it is believed that the pre-existing internal efficiencies create resistance to innovation. PC activity (the sequential activities that performed by PC are called as PC activity in this paper) can be an effective means to break through the obstacles to implement innovation.

This research started from the awareness of two problems. First, how are PC studies discussed so far; what are the challenges and which direction should be taken in the future? Next is a question related to empirical research: based on the tendency of PC study, what points should be considered in terms 
of theoretical and practical aspects in order to advance PC study further?

The purpose of this research is two-fold. Both are based on our original standpoint. First one is to clarify the issues in previous study and suggest the direction of problem solving. Another one is to make propositions for survey in Japan.

In order to search for answers and aims to these problem awareness, first we will review the previous studies. Next, we will summarize the previous studies and organize the challenges. In addition, we will also look at the problems found, search for directions, and finally draw a conclusion.

\section{Methods}

First of all we review the on previous studies about PC. PC research field can be divided to definition of a $P C$, background of PC emergence, behavioral characteristics and roles, personal characteristics and comparison with nationality.

After Schon [9] described and defined PC, in the 1970s Chakrabarti [11] and Rothwell et al. [12] developed the concept and showed the existence of $\mathrm{PC}$ as a success factor for innovation in more details. In the early 1980s, centered on Howell and Markham, PC studies became more active and were conducted on various topics from the initial PC definition to the reason why $P C$ emerge or on the reasons and background of the increase of demand on PC. Furthermore, empirical studies on behavioral characteristics and roles, such as how existing PCs are active and how they are portrayed by the surroundings, were conducted. Afterwards, studies on the individuals who perform such roles, such as the knowledge or experience that they have or their personal characteristics, have also been performed. Meanwhile, with the multi-nationalization of various companies, Shane et al. conducted a country-based comparison study, focusing on the differences in various cultural values. In this section, we arranged the previous studies based on each item by focusing on the history of PC studies.

Incidentally, there are some discussion that champion activities are described as a function "championing" [10] or that the combining of multi-persons' activities shows champion performance [13]. This concept is based on the policy that each person should not be treated as a hero/heroin. However, the aim of this research attempt to clarify the relationship of some issues relevant with champion, like personal characteristic, role, experience and so on. Therefore, this research highlights individual champion

There are 3 types of PC study: those that view the success factors of the new product development as one important element, those that try to understand one key person, and those that focus on PC itself [14]. First type of PC study basically captures just one success factor of innovation and PC is treated as well other factors like process and organization. The contributions by PC to successful innovation are mentioned in such studies, but specific issues like behaviors or strategies of PC are not touched so much. Second type perceives PC as one of key persons who affects to successful innovation and compares with other key persons like gatekeepers or sponsors. As a result, the differences of roles by key persons are focused on and other issues are missing. In this study, we will review those that focus on PC itself because such third type discusses deeply the rich relevant issues to PC those are not only contributions or roles but also behaviors, personal characteristics, strategies and functions.

\section{Definition of a PC}

Schon [9], who first outlined the meaning PC, defined PC as a person who has the authority and confidence, and uses the informal systems and relationships within the company to exercise influence among different departments.

Afterwards, Chakrabarti [11] brought innovation to an organization beyond the organizational hierarchy and one's own role, Maidique [1] is an organization member who created, defined, and adopted the idea of new technological innovation, and was known to be a person who risked position and fame to promote innovation.

Table 1 PC definition.

\begin{tabular}{|c|c|}
\hline $\begin{array}{l}\text { Taylor, Cocklin, } \\
\text { Brown and } \\
\text { Wilson-Evered } \\
{[32]}\end{array}$ & $\begin{array}{l}\text { Engage in context-sensitive leadership processes that } \\
\text { typically involve other leaders (such as formal leaders) as } \\
\text { well as followers. }\end{array}$ \\
\hline $\begin{array}{l}\text { Howell, Shea and } \\
\text { Higgins [6] }\end{array}$ & $\begin{array}{l}\text { An individual who informally emerges in an organization } \\
\text { and makes a decisive contribution to the innovation by } \\
\text { actively and enthusiastically promoting its progress } \\
\text { through critical stages. }\end{array}$ \\
\hline \multirow{6}{*}{$\begin{array}{l}\text { Markham and } \\
\text { Aiman-Smith [24] }\end{array}$} & An individual who: \\
\hline & $\begin{array}{l}\text { 1. Recognizes a new technology or market opportunity as } \\
\text { having significant potential. }\end{array}$ \\
\hline & 2. Adopts the project as his or her own. \\
\hline & 3. Commits personally to the project. \\
\hline & $\begin{array}{l}\text { 4. Generates support from other people in the } \\
\text { organization. }\end{array}$ \\
\hline & 5. Advocates vigously for the project. \\
\hline Shane [7] & $\begin{array}{l}\text { Are motivated to absorb the risk of overcoming } \\
\text { organizational obstacles to innovation because they have } \\
\text { different preferences from the majority of organization } \\
\text { members for six championing roles. }\end{array}$ \\
\hline Maidique [1] & $\begin{array}{l}\text { A member of an organization who creates, defines, or } \\
\text { adopts an idea for new technological innovation and who } \\
\text { is willing to risk his or her position and pre-stage to make } \\
\text { possible the innovation's successful implementation. }\end{array}$ \\
\hline Chakrabarti [11] & $\begin{array}{l}\text { An individual who is intensely interested and involved } \\
\text { with the overall objectives and goals of the project and } \\
\text { who plays a dominant role in many of the research- } \\
\text { engineering interaction events through some of stages, } \\
\text { overcoming technical and organizational obstacles and } \\
\text { pulling the effort through its final achievement by sheer } \\
\text { force of his will and energy. }\end{array}$ \\
\hline Schon [9] & $\begin{array}{l}\text { Willing to put him on the line for an idea of doubtful } \\
\text { success. Willing to fail is capable of using any and every } \\
\text { means of informal sales and pressure in order to } \\
\text { success. }\end{array}$ \\
\hline
\end{tabular}

In those early PC studies, it was common for individuals in informal positions with innovative technological ideas in the research and development (R\&D) department within a large company, to defend their ideas so they do not stop along the 
way and to take risks willingly. Subsequently, this definition is deepened as shown in Table 1.

\section{Background of PC emergence}

Schon showed the differences between fail and success for launch the innovative and successful ideas which had PC [9]. Chakrabarti clarified the projects with PC is high successful rate [11]. Howell and Higgins compared the projects that has champion with the ones has non-champion. They revealed the influence tactics by PC was effective to radical innovation [15]. Markham et al. insisted necessities of PC for radical ideas to beyond the valley of death [16]. Thus innovations, especially radical innovations often require emerge of PC.

The following section can classify the situation of PC emergence, the process of new product development, and the relationship of $\mathrm{PC}$ with innovation.

First, by focusing on the rise of antagonists against innovation, Markham, Green and Basu [5] tried to clarify the relationship between PC and its antagonists. They had a strong interest in what kind of situations did PCs emerge and investigated 213 US projects in which PCs existed. They showed 2 important results. One of them is that there were almost no suggested relationships between PC and antagonists against innovation. Another one is that there were cases where multiple PCs exist in one project, not only in R\&D, but also in marketing and administrative divisions, even among users. These, combined with the relationship of PC and process, has greatly expanded the application scope of PC studies, and gave rise to the opportunity to discover common grounds of PC and marketing research.

Regarding the relationship of PC and process, Burgelman [10] argued that the process of development was divided into four stages as Definition, Impetus, Strategic Context, and Structural Context and that PC is particularly important at the early stages, from definition to promotion. Likewise, Markham [17] defined the development process as Discovery, Support, Approval, and Launch; and the activities of a product champion, such as the preparation of Business Case Outline and process approval documents, are particularly important in the upstream processes from discovery to support stages to "cross the valley of death". Furthermore, Howell and Boies [18] reported on the appearance and activity of PCs, capturing only the upstream processes of idea creation and promotion. More specifically, it was strongly pointed out that PC activity is important before the official development, in other words at the front end of innovation $[16,19,20]$, particularly because on there are big challenges at the upstream processes.

Finally, in relation to innovation, Schon [9] who first defined PC, mentioned that "the new idea either finds or die" because it is easy for innovative new products to encounter resistance within the organization and they are often not materialized if there are no such thing as a PC. In addition, Chakrabarti [11], who focused on the decision-making process on the success or failure in the development of new innovative products, mentioned about PC's positive contribution to the positive result of transcending formal organizational roles. In addition,
Maidique [1] discussed that if there are no market innovations then true innovations will not exist, and highlighted the importance of PC emergence in the role of connecting engineers and entrepreneurs. Howell and Higgins [15] compared the effects of PC presence or absence, pointed out that PCs have higher tendency of risk-taking and innovating, and revealed that they use diverse influence tactics. That is, a supportive environment for innovation will facilitate PC emergence. In addition, Markham [17] has revealed the elements required for PC activity by relating the dangers of termination, which often threaten the development of innovative products, and the roles of PC in overcoming them. Furthermore, as to the hierarchy of $P C$ emergence, there was a discussion that radical innovations usually emerge from the senior level [21]. Thus, radical innovation is, the greater the resistance in the organization will be, and there will be more demand on PC emergence, causing a higher possibility for PC to appear; all of which are consistent views in PC studies.

\section{Behavioral characteristics and roles}

With regard to behavioral characteristics and roles, because the characteristics have to be expressed as PC studies progress, it is the main factor within the definition of a PC.

Shane [7] defined six roles of PC. Those are, to provide people with autonomy from the rules, procedure and systems of the organization, to gather organizational support by building coalitions, to use the looseness of monitoring mechanism, to establish decision-making mechanism, to use informal means to persuade the members of the organization, and to protect the innovation team from interference by the organizational hierarchy. All of them are necessary actions to overcome obstacles in the organization that stands in front of those who intend to promote innovation from conventional standards and rules.

Meanwhile Markham [17] cited nine points while associating with each process from research to marketing. Those are Discover that the research has commercial value, Manifest the discovery as a product, Communicate the potential through a compelling business case, Acquire resources needed to establish potential, Use resources to reduce risk, Seek approval of the project for formal development, Translate the project into the criteria used for approval, Decide to approve or not approve project, and Develop and launch the product.

In both cases, there are consistent characteristics in informing the usefulness of ideas within the organization, obtaining support within the organization, acquiring resources, and implementing environmental improvements for idea materialization $[2,8,10,19,22,23]$. In addition, from the viewpoint of intra-organizational adjustments, the word "political" is sometimes used $[4,11,24,25]$. At this time, the main behavioral characteristics and roles of PC are, rather than directly solving the technical problems to implement the idea into a product, to promote innovation drivers, and to actively engaging in activities to implement innovations inside and outside the organization. 
On the other hand, the behaviors covered in the study of Howell, Shea and Higgins [6] are different from those covered in the other studies. They conducted an interview and questionnaire survey on 45 PCs, 47 senior management and 216 team members, and selected 15 core universal items from 102 activity items. These items expressed how PCs that perform such activities look like from the surroundings, rather than as a concrete way of how PCs work.

\section{Personal characteristics}

Personal characteristics are common arguments in the definition of a PC. They are closely related to the following characteristics: pro-active, risk-taker, energetic, and aware of owns roles. Some of those are based on predisposition. Other than those, there are other sophisticated characteristics that each PC develops individually, learned through education and work experience $[7,8]$.

Shane [7] suggested that deviant preference is the most important natural personal characteristic of a PC. This argument was based on the idea that the drive leads to the significance of PC existence and that the organization efficiency and the implementation of innovation are contradictory one to another. In other words, when trying to implement innovation, people encounter obstacles in the form of opposition from the majority of organizational members who prioritize the existing rules, disciplines, or procedures. PCs act by trying to overcome the obstacles, as PCs originally developed based on the argument that PCs are individuals who are allowed to think differently, has less psychological resistance to deviation, and is able to diverge progressively. On the one hand, closely related to the previous behaviors, other important characteristics of PCs are charismatic $[20,26]$, persistent $[20,26]$, flexible [26], socially independent [26], etc.

On the other hand, knowledge, skills, technology, etc., are cited to be acquired through education and work experience. Specifically, it is important to understand technical knowledge $[11,22,27]$, human relations and political skills $[23,25,28]$, authority $[7,23,26]$, network $[7,22,27,29]$, influential tactics $[20,26]$, and others. From these factors, it can be inferred that a $\mathrm{PC}$ has a long service life and has a relatively high rank in the organizational hierarchy.

Furthermore, it is worthy to note that there are characteristics that cannot be categorized as congenital or acquired characteristics, as they overlap with each other. Some examples are driving force $[11,26,28]$ and persuasiveness $[7,20,24]$. And looking at these personal characteristics, the conventional premises that not everyone can become a PC is understandable. In other words, someone who has potentially constant characteristics and who later acquire and accumulate knowledge and skills can emerge as a PC when triggered by a certain circumstance [7].

\section{Comparison with nationality}

The other recent trend in PC studies is to clarify the influence of cultural differences on PC activities and personal characteristics. Against this backdrop, there is a tendency that corporations that try to drive innovation are becoming increasingly multinational as production bases and market bases are dispersed around the world. In other words, it is important to show what points should be dealt with universally, and what points must be individually, and to show those points specifically.

First, Shane [7] argued in large organizations, rules, procedures, and standards that are set up to improve the efficiency of an organization, by division of labor and limitation of excessive information flow, are obstacles for inherently uncertain innovation. On that basis, PCs prefer to deviate from the existing rules, procedures, and standards and play a role to implement innovation. Furthermore, they conducted empirical research on 43 organizations in 68 countries and proceeded analyses based on previous research on human resource management that mentioned the strong influence of the subject's country of origin. Their results revealed that in any national structures, there are six common roles in championing that are preferred. Furthermore, they insisted that the characteristics of individuals who like to deviate are in line with the entrepreneurial spirit, regardless of the culture of the country, and those individuals usually play a role as entrepreneurs in self-founded and small companies or as PCs within an organization. Subsequently, Shane co-developed it with other researchers.

At first, Shane, Venkataraman and Macmillan [2] formulated a theoretical hypothesis about what type of championing is preferred, focusing on the differences in cultural values of individualism/collectivism, high/low power distance, and avoidance/acceptance of uncertainty. Secondly, Shane, Venkataraman and Macmillan [8] examined this hypothesis. Their results supported many hypothesis and showed that in organizations with a culture that avoids uncertainty, championing is preferred among organizational standards, rules, and procedures, whereas in organizations with culture that has a high power distance, it is desirable to obtain instructions from a person with power before starting innovation activities, and in organizations that show high collectivism, it is desirable to obtain supports from various divisions. This series of research was based on the research on national culture by Hofstede [30], which studied indirectly about what kind of cultural value each country has about the avoidance/acceptance of uncertainty, high/low power distance, and individualism/collectivism, and the series of research is related to the study done by Hofstede [30]. In other words, Shane et al. described the similarities and differences in the cultural values of various countries. However, as they pointed out, comparison of the actual championing activities with the preferred and easy-to-accept championing should be performed in the future.

On the other hand, studies that compared many countries such as Shane et al. require more detailed item setting and precision is often impaired. Studies that compare 2 countries were done. Lee Jaehee, Lee Jinjoo and Souder [31], compared the differences in PC activities in South Korea and the United States based on the differences of oriental and western cultures. Their results showed that participation in decision making, interdepartmental integration, PC influence, etc., have the same 
impact on NPD (New Product Development) performance worldwide, regardless of culture. In contrast, the use of internal venture, organization structure, concentration of authority, etc., have different impacts on NPD performance in South Korea and the US. Other than this study, comparative studies between Germany and the United States [29], and between France and Germany [23] have also been conducted.

In the future, innovation activities are not limited to production bases; R\&D and marketing activity bases are expected to be more and more diversified. The need of elaborate studies, involving large-scale surveys comparing a large number of countries or specific surveys comparing two or three countries, are expected to increase. The important thing in that case is national culture clearly affects to the PC activity $[2,7,8,23,29]$. In other words, $P C$ is subject to restrictions of their action because organizational members don't tolerate PC roles that do not suit their preference [7]. Therefore, the viewpoint how executives or managers use PC activity with the background of national culture is indispensable for PC study.

\section{Situation of PC studies}

In the second paragraph, we reviewed the six categories: definition, emergence, behavioral characteristics, personal characteristics, nationality, and extended field. As mentioned in the text, as research related to PC advances, the focus of research is shifting gradually. In addition, efforts to model these outcomes have gradually become evident. A summary is shown in Figure 1.

In sprouting stage, PC was discovered and the concept of PC has recognized. Definition and behavioral characteristics have started to discuss. Those are arguments about how and why PC contributes to successful innovation. After that, interest of researchers has extended to emergence. Researchers tried to reveal the reasons of PC emergence. Those backgrounds of emergence included the relationships between the locations or functional departments in organization, the steps of innovation process and radicalness of innovation. Furthermore, personal characteristics of PC were focused on. Backgrounds of emergence are external stimulation to $P C$, on the other hand personalities of PC relates to internal motivation for PC emergence.

In evolution stage, some factors like backgrounds or personalities were structured as a model to realize mechanism of emergence or innovation success. Additionally, some researchers paid efforts to cultural aspects. Because different types of PC were found out in different types of organizations with based on business globalization. At present, discussions are extending to some directions. One of them is trying to depict PC as not only a key person but also the function of champion. Some researchers insisted PC skill is one of leadership styles. Another direction is extension of business aspects. Not only physical product development but also invisible service development are included in PC study and PC was found out in not only manufactures but also information technology industry, construction firms and health care products. We call this expand stage.

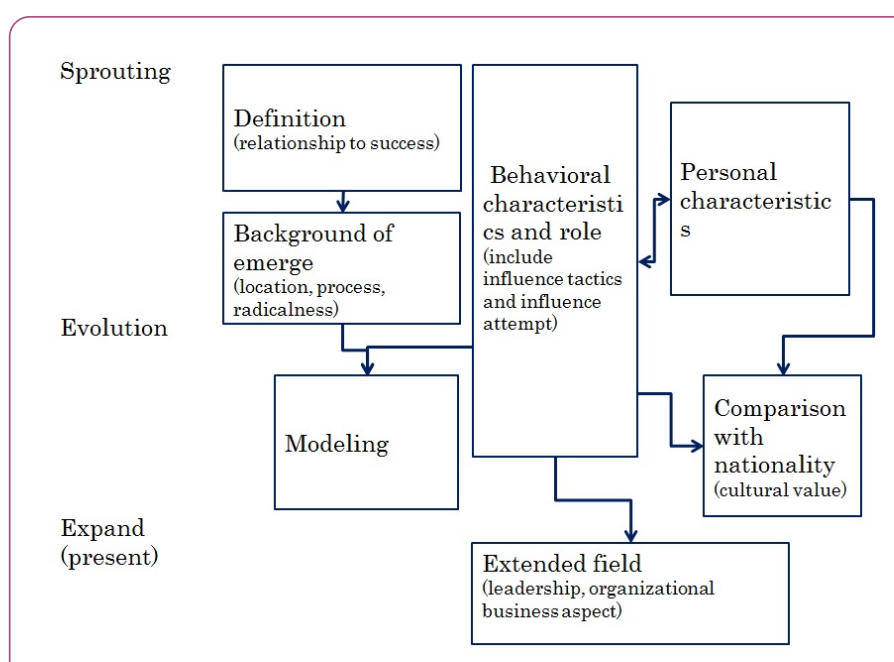

Figure 1 Perspective of PC study.

\section{Discussion}

\section{Issues in previous studies}

The knowledge of project manager has been studied by many researchers and the whole of them have established well for cultivation of project manager [32]. On the other hand, PC study is not enough so far. Table $\mathbf{2}$ expresses the comparison of project manager and product champion [14]. In a PC study, each researcher set the central theme according to each problem awareness, and conducted empirical research. For this reason, the definitions and concepts of many ambiguous words were left untouched. For this reason, the general issues have not been clarified. Here, we will focus on exploring the essentials.

Table 2 Comparison between project managers and product champions [14].

\begin{tabular}{|c|c|c|}
\hline & Project Manager & Product Champion \\
\hline $\begin{array}{l}\text { Appointment } \\
\text { arrangements }\end{array}$ & Appointed at the project start & $\begin{array}{l}\text { Often emerge or are } \\
\text { specified later }\end{array}$ \\
\hline Formality & $\begin{array}{l}\text { Given responsibility and } \\
\text { authority from senior } \\
\text { management }\end{array}$ & $\begin{array}{l}\text { Spontaneously appear } \\
\text { and use an informa } \\
\text { network. }\end{array}$ \\
\hline $\begin{array}{l}\text { Connection to } \\
\text { the level of } \\
\text { innovation }\end{array}$ & $\begin{array}{l}\text { Heavily involved in the } \\
\text { success of the project } \\
\text { regardless of the level of } \\
\text { innovation }\end{array}$ & $\begin{array}{l}\text { Extent of contribution to } \\
\text { project success increases } \\
\text { when innovation is greater }\end{array}$ \\
\hline $\begin{array}{l}\text { System of } \\
\text { knowledge }\end{array}$ & $\begin{array}{l}\text { Project management } \\
\text { systems and processes }\end{array}$ & $\begin{array}{l}\text { Definition and behavior } \\
\text { are clear, but mechanism } \\
\text { of occurrence is unknown }\end{array}$ \\
\hline Education & $\begin{array}{l}\text { Systematically trained and } \\
\text { qualified }\end{array}$ & No specific training \\
\hline
\end{tabular}

Outline of PC study: Three researchers, Howell, Markham, Shane, have presented many papers in PC study and have presented important results that are often referred by other researchers. 
Firstly, Howell's studies have been trying to define championing by PC while comparing the differences between whether championing is present or not. The studies are based on when a PC emerges, the background of product innovation, etc. Likewise, Markham focused on PC activities, but tried to clarify the subjects of championing and to consider the influence on those subjects. As a result, PCs emerge in various functional departments where antagonists appear, not only in the R\&D department, but these studies about antagonists have not been expanded since then. Furthermore, Markham was interested in the relationship between championing and project performance and tried to model it. Finally, Shane's studies clarified the role of PCs and looked into the relationship between the characteristics of cultural values arising from the differences in physical locations among countries, the role of $\mathrm{PC}$, and the preferences for PC activities (what kind of activities are preferred). Shane's studies have shown the common and contrasting points based on the differences in cultural values. In recent years, this champion concept is extending to business creation [33,34] or other field like health care [35] with new sight like leadership of champion or relationship of organizational behavior.

Features of PC study: Along with the management team and project managers, PC studies, which investigate human resources who have a great influence on NPD and have the following five features.

First of all, PC activity is based on the word "informal". This originated from an organizational nature that closely resembles the nature of innovation, which is the breaking and bending of existing standards and rules to implement innovation. Therefore, even if the relevant project becomes official following the formation of consensus within the organization, at least when PC activity starts, the project are forced to deviate from these standards and rules, and still be carried out informally. That is the demand for PC; it is also the significance of PC existence. In addition, after project started formally, PC activity as informal one is required to solve the technical or commercial obstacles while changing its roles or functions [17].

Next, PC is concerned with specific ideas and products. The higher level an innovation is at, the easier it is for a PC to emerge. Or, no matter how innovative it is, depending on the judgment and interests of the PC itself, it may respond to some ideas and products, and may not so some. This is clearly distinct from the managerial positions in organizations, and it is also different from the positions officially appointed by the organization, like a project manager. Therefore, organizational management is particularly difficult with PC emergence.

Furthermore, it is closely related to the innovation process. Markham discovered that PC activity is particularly important in the upstream side, and PC activity changes as the process progresses. It seems natural that changes from informal to formal as the result of consensus formation mentioned above affect PC activities.

Furthermore, it was reported that PC is related to cultural value. This is a very encouraging preliminary data when we are about to start PC studies in Japanese companies where they have not been actively performed yet.
Finally, substantial number and scale of empirical research are being conducted, mainly on PC activities and roles, and the results of empirical research are accumulating. As pointed out earlier, there are still ambiguous, overlapping and missing points, but the accumulation of knowledge related to PC is useful for the innovation activities in many companies.

The above five features can be summarized for be the value of PC study.

Challenges of PC study: PC study has a high research value because it investigates human resources that lead innovation to success; however previous studies have many challenges. As a fundamental thing, as already mentioned, an overview of this research area is still not presented. Other than that, bellow issues are the other challenges.

First, the success of innovation is not clearly defined. In the early studies by Schon [9] and Chakrabarti [11], innovation is defined as successful when it is implemented. As the discussion of PC activities gradually became active, the idea of relating innovation success with the company's performance expanded temporarily, but now the mainstream is focused on project performance. It is not clear how to measure project performance with existing indicators and relate it to the effects of PC activity. In particular, there are also cases where long-term orientation and relevance to success at the business level are used $[33,34]$, however these are thought to expand the PC concept too much.

Next, as pointed out by Markham et al., although innovation process is a prerequisite, many studies did not necessarily mention processes. Especially, in studies that compared countrybased cultural values, this factor has been rarely discussed. There is also a lack of empirical studies that show how PC activity changed with the progress of NPD process series.

In addition, we place too much emphasis on surveys by largescale questionnaires, and there is a lack of detailed individual interview surveys. Investigation by survey forms often has difficulty in communicating detailed intentions to respondents, and there is a possibility that the reliability of the survey is impaired because of the misunderstandings that accompany it. In particular, Japan was included in Shane's target countries, but PC research is still rare in Japan, and there is room for doubt whether survey subjects responded with sufficient understanding.

\section{Consideration about the issues}

Overview of PC study: Firstly, it is necessary to organize the words and concepts. In particular, it is necessary to specify the differences between "act (action)" or "activity," "behavior," and "function," which were discussed by Howell and Markham, with "role" that was discussed by Shane. We propose the following definitions:

Role: The duty that the PC sets by him/herself and is not included in the organizational structure. It consists of several functions. 
Function: A work that affects an organization, exerted as the result of single or multiple actions such as persuasion, negotiation, mediation, etc.

Action (act or activity): Concrete movements taken by PC. Expressed as verbs such as meeting, walking, talking, etc.

Conduct (narrow sense of behavior): The situation of a PC that a third party feels when it acts. Expressed in emotional language such as passionate, enthusiastic, tenacious, etc.

Influence tactics, influence attempt: A policy that becomes the basis for taking concrete actions and conducts for the purpose of playing a role.

Behavior (broad behavior): A collective term for roles, functions, conducts, behaviors, influence tactics, and influence projects adopted by PCs to influence organizations.

Personal characteristics (personality, character): A collective term such as the ability, character, tendency of thought, which the PC inherently has as a person (individual). Include both innate and acquired characteristics.

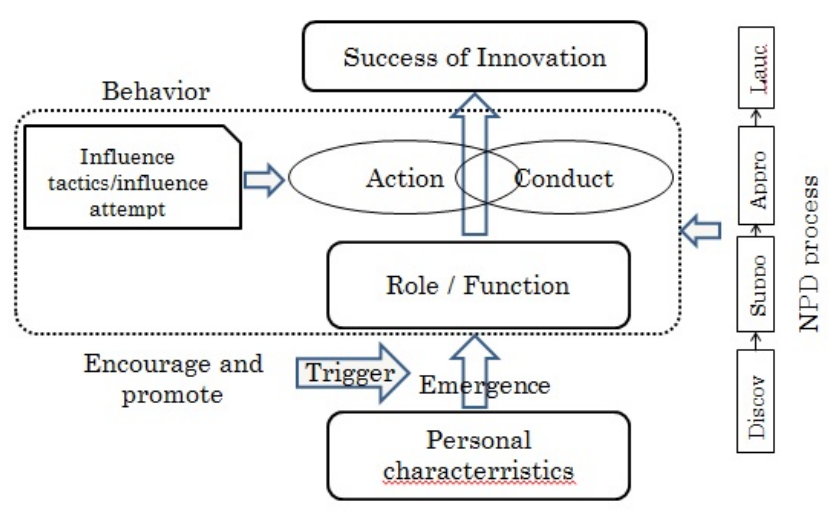

Figure 2 Overview of PC study.

PC emerges personal characteristics were stimulated and triggered by some sort of event under the conditions that the organization set various measures such as rewards that encourages spontaneity, etc. As the NPD process progresses, PCs express their activities and encourage organizations to recognize their existence from the surroundings. Figure $\mathbf{2}$ shows these relationships.

Each researcher's interests and attentions can be understood by organizing them in the following way: Howell emphasized on activity and conduct, Markham focused on role, function, influence tactic, and influence attempt in the NPD process, and Shane dealt with relationships between role function and personal characteristics based on cultural values.

Direction of problem solving: Next, we will discuss some related issues. First of all, evaluation of the results that PC activities give to NPD should not be greatly influenced by factors other than individual NPD such as performance, and by factors with varied indicators that depend on the industry type, such as project performance. Given that the PC activities are spreading to innovation development in various industries, it is reasonable to go to the point that the definition of success returns to the origin and the idea of innovation leads to the implementation of a new product. What we must emphasize again is that the attitude of pursuing organization efficiency as a whole to protect existing standards and rules is an obstacle to innovation activities that implement ideas to form new products. In other words, the starting point of PC research lies in the requirement of a PC to overcome this obstacle. From this viewpoint, it is understood that when a PC is involved, NPD and innovation activities are synonymous. A PC is required for radically innovative NPDs, and new products from radically innovative NPDs are regarded as the implementation of innovation in the society, and the organization that executes the NPD also innovates internally.

In addition, as Shane pointed out, other champions like innovation champion, technology champion, idea champion, product champion, organizational champion, executive champion, or even sponsor can also be included in PC studies, from the standpoint that it is the PC that removes obstacles to implement innovation ideas into the form of new products. Individuals who take Shane's defined roles and behaviors or Howell's and Markham's influence tactics can be regarded as PCs.

By summarizing the overview of PC study in this way, it became possible to define the ambiguous words and concepts, and to determine the boundaries of success and champion, which were different among researchers.

Finally, there are still problems related to investigation methods and detailed tracking. These two points are mutually related tasks and can be resolved with the same directionality. A large-scale questionnaire survey is valuable to many companies operating globally and has a high research value, but on the other hand it is the greatest common factor and at the same time burdens the survey respondents in setting many questions. However, as shown in the overview picture, it is difficult to capture the entire PC activity that changes over time unless process is taken into account. Here, it seems that there is the barrier on present $\mathrm{PC}$ research. In order to solve the stagnation of the PC research as a whole and to revitalize it, detailed research is required in addition to the overview map. Recently studies on research are starting to focus on resource mobilization. Takeishi, Aoshima and Karube [36] performed detailed observation of examples of innovation that successfully brought economical values and were evaluated by the society and described the route to bring resource mobilization by justified innovation in the organization. Similar to PC studies, this research on resource mobilization also focused on how to form consensus within the organization and how to proceed with it officially while removing obstacles to innovation within the organization. The difference between these two studies lies at how to grasp the innovation process, whether viewed from the organization as a whole or through PCs a human resources. PC studies as well as studies on resource mobilization seem to have reached a stage in which they follow the process carefully and overlook in detail the effects of PC activities on the organization. For that purpose, as done in studies on resource mobilization, a method of repeating an interview survey for 
each innovation case is appropriate. By adopting such method, it is possible to understand from a new point of view how the actions, conducts or influence tactics accumulated in previous PC studies are applied in the organization, acquire consensus, and led to the acquisition of resources, dynamically in a timedependent manner. Then, studies on PC activities will be deepened again.

Propositions for survey in Japan: In this section, seven propositions are suggested based on obtained knowledge through the review of previous studies and consideration about the issues, as researches of PC in Japan will be advanced forward.

Nakata and Sivakumar mentioned that Confucian dynamic influences on Japanese innovation. They emphasized Japanese long-term orientation in comparison with some western countries' short-term orientation like the US or UK [37]. Managers in Germany that culture is similar to Japan takes long time to get promotion in compared to France [23].

Proposition 1: PC in Japanese firm is cultivated for long time and gradually become to play the role and function as PC.

Many Japanese firms are presented typical collectivism society [30]. Shane revealed the differences of undesirable PC styles that are based on cultural aspects. For example, in Japan innovators don't violate standard procedures or rules but innovators don't adhere standard procedures or rules in United Kingdom. Or, support from employees don't be required before formal approval by senior manager in Japan but formal approval don't be sought without employees' support in UK [38]. On the other hand, Shane, Venkataraman and Macmillan [8] pointed out that in organizations that show high collectivism, it is desirable to obtain supports from various divisions. Those findings between Shane [38] and Shane, Venkataraman and Macmillan [8] look includes contradictions. Additionally, Shane, Venkataraman and Macmillan [8] showed that in organizations with a culture that avoids uncertainty, championing is preferred among organizational standards, rules, and procedures.

Proposition 2: PC in Japanese firm takes influence tactics to aim wide consensus formation in considering for collectivism.

Proposition 3: PC in Japanese firm has two ways for wide consensus formation and use properly according to circumstances. Those are higher different priorities, one of them is formal approval by senior management, another one is supports from various departments.

Proposition 4: PC in Japanese firm takes influence tactics to the innovation inside of the existing the rules or procedures in considering for uncertainty avoidance.

Preferred influence tactics are different in various cultures [8]. In other words, different PC is found out by investigating influence statics of PC. Furthermore, there are many empirical researches about PC activities and behaviors [4-7,11-15-17,19-26,29,31,33,34] because it is clear method to specify who is PC. The relationships of issues were depicted as Figure $\mathbf{2}$ in this paper.
Proposition 5: Survey for PC in Japanese firm should be taken for influence tactics after PC is specified by his/her activities and behaviors.

Proposition 6: PC in Japanese firm takes different roles and functions from PC in western firm.

Proposition 7: PC in Japanese firm has different personal characteristics from $P C$ in western firm.

PC study in Japan should be taken with reference to the results of previous empirical surveys from now on. Seven propositions have been gained for that progress.

\section{Conclusion}

Finally, we summarize the results of this research and draw a conclusion. In this paper, PC study was divided into five categories and reviewed, and the background of the research area as a whole was arranged. We covered five common issues. Furthermore, to solve the problems, words and concepts were redefined and a concept showing the relationship of elements to be composed is summarized in Figure 2 showing the overview. Then, we examined the problems related to the investigation method, which had not been solved previously, in the discussion part and presented the direction of future research. As a result, we were able to find a breakthrough to advance $P C$ research which has been somewhat stagnant. This appearance diagram presents the foundation on which common words and concepts used by individual researchers can be unified, to help overcome many research problems, which can be expected to lead to a new framework. Furthermore, propositions for survey in Japan are suggested. In addition, we could demonstrate the direction of future research, which is to investigate and fine-track the temporal process using an interview survey method and relate it with the elements centered on PC activity accumulated so far. Based on the knowledge related to the cultural value described by Shane et al., it is expected that the above points will energize PC studies in Japan and eventually the entire PC research will progress further.

Note: This article has been reviewed by two peer-reviewers.

\section{References}

1. Maidique MA (1984) Entrepreneurs, Champions, and Technological, Innovation. IEEE Engineering Management Review 12: $24-40$.

2. Shane SA, Venkataraman S, Macmillan IC (1994) The Effects of Cultural Differences on New Technology Championing Behavior within Firms. The Journal of High Technology Management 5: 745-772.

3. Shane SA (1995) Uncertainty Avoidance and the Preference for Innovation Championing Roles. Journal of International Business Studies 26: 47-68.

4. Markham SK (2000) Corporate Championing and Antagonism as Forms of Political Behavior; An R\&D Perspective Organization Scienc11: 429-447.

5. Markham SK, Green SG, Basu R (1991) Champions and antagonists: Relationships with R\&D project characteristics and 
management. Journal of Engineering and management 8: 217-242.

6. Howell JM, Shea CM, Higgins CA (2005) Champions of product innovations : defining, developing, and validating a measure of champion behavior. Journal of Business Venturing 20: 641-661.

7. Shane SA (1994) Are Champions Different from Non-Champions? , "Journal of Business Venturing 9: 397-421.

8. Shane SA, Venkataraman S, Macmillan IC (1995) Cultural Differences in Innovation Championing Strategies. The Journal of Management 21: 931-952.

9. Schon DA (1963) Champion for Radical New Inventions. Harvard Business Review 41: 77-86.

10. Burgelman RA (1983) A Press Model of Internal Corporate Venturing in the Diversified Major Firm. Administrative Sciense Quarterly 28: 223-244.

11. Chakrabarti AL (1974) The Role of Champion in Product Innovation. California Management Review 17: 58-62.

12. Rothwell R, Freeman C, Horlsey A, Jervis VTP, Robertson AB, et al. (1974) SAPPHO Updated-Project SAPPHO Phase . Research Management 19: 258-291.

13. van Laere J, Aggestam L (2016) Understanding champion behaviour in a health-care information system development project-how multiple champions and champion behaviours build a coherent whole. European Journal of Information Systems 25: 47-63.

14. Fujii S (2012) The Relationship between Project Manager and Product Champion in New Product Development -Search for Product Champions in Japanese Firms. Journal of International Association of Project and Program Management 6: 141-151.

15. Howell JM, Higgins CA (1990) Champions of technological innovation, Administrative Science Quarterly 35: 315-341.

16. Markham SK, Ward SJ, Aiman-Smith L, Kingon AI (2010) The valley of death as context for role theory in product innovation. Journal of Product Innovation Management 27: 402-417.

17. Markham SK (2002) Moving Technologies from Lab to Market. Research-Technology Management 45: 31-42.

18. Howell JM, Bois K (2004) Champions of Technological Innovation: the Influence of Contextual Knowledge, Role Orientation, Idea Generation and Idea Promotion on Champion Emergence. The Leadership Quarterly 15: 123-143.

19. Mansfeld MN, Hölzle K, Gemünden HG (2010) Personal characteristics of innovators-an empirical study of roles in innovation management. International Journal of Innovation Management 14: 1129-1147.

20. Markham SK (2013) The Impact of Front-End Innovation Activities on Product Performance. Journal of Product Innovation Management 30: 77-92.

21. Slater SF, Mohr JJ, Sengupta S (2014) Radical product innovation capability: Literature review, synthesis, and illustrative research propositions. Journal of Product Innovation Management 31: 552-566.

22. Chandy RK, Tellis GJ (1998) Organizing for Radical Product Innovation: The Overlooked Role of Willingness to Cannibalize. Jornal of Marketing 35: 474-487.
23. Roure $L$ (2001) Product champion characteristics in France and Germany. Human Relations 54: 663-682.

24. Markham SK, Aiman-Smith L (2001)Product Champions: Truths, Myths and Management. Research-Technology Management 44: 44-50.

25. Weissenberger-Eibl MA, Teufel B (2011) Organizational politics in new product development project selection: A review of the current literature. European Journal of Innovation Management 14: 51-73.

26. Jenssen JI, Jorgensen G (2004) How Do Corporate Champions Promote Innovations? International Journal of Innovation Management 8: 63-86.

27. Vowles N, Thirkell P, Sinha A (2011) Different determinants at different times: B2B adoption of a radical innovation, Journal of Business Research 64: 1162-1168.

28. Beatty CA, Gordon JR (1991) Preaching the gospel: The evangelists of new technology, California Management Review 33: 73-94.

29. Gemünden HG, Salomo S, Hölzle K (2007) Role Models for Radical Innovations in Times of Open Innovation. Creativity and Innovation Management 16: 408-421.

30. Hofstede G (1983) National Cultures in Four Dimensions: A Research-based Theory of Cultural Differences among Nations. International Studies of Management \& Organization 13: 46-74.

31. Lee Jaehee, Lee Jinjoo, Souder WE (2000) Differences of Organizational Characteristics in New Product Development: Cross-Cultural Comparison of Korea and the US. Technovation 20 : 497-508.

32. Kerzner HR (2013) Project management: a systems approach to planning, scheduling, and controlling. John Wiley \& Sons.

33. Taylor A, Cocklin C, Brown R, Wilson-Evered E (2011) An investigation of champion-driven leadership processes. The Leadership Quarterly 22: 412-433.

34. Walter A, Parboteeah KP, Riesenhuber F, Hoegl M (2011) Championship Behaviors and Innovations Success: An Empirical Investigation of University Spin-Offs. Journal of product innovation management 28: 586-598.

35. van Laere J, Aggestam L (2016) Understanding champion behaviour in a health-care information system development project-how multiple champions and champion behaviours build a coherent whole. European Journal of Information Systems 25 47-63.

36. Takeishi A, Aoshima Y, Karube M (2010) Reasons for innovation legitimizing resource mobilization for innovation in the cases of the Okochi Memorial Prize Winners, in Dynamics of Knowledge. Corporate Systems and Innovation, Springer Berlin Heidelberg.

37. Nakata C, Sivakumar K (1996) National culture and new product development: An integrative review. The Journal of Marketing 60 61-72.

38. Shane S (1994) Championing innovation in the global corporation Research-Technology Management 37: 29-35. 